\title{
Estimation of aboveground biomass using aerial photogrammetry from unmanned aerial vehicle in teak (Tectona grandis) plantation in Thailand
}

\author{
SASIWIMOL RINNAMANG ${ }^{1}$, KAMPANART SIRIRUEANG $^{2}$, SORAVIS SUPAVETCH ${ }^{3}$, \\ PONTHEP MEUNPONG ${ }^{1, \vee}$ \\ ${ }^{1}$ Department of Silviculture, Faculty of Forestry, Kasetsart University. Bangkok 10900, Thailand. Tel./fax.: +6685-319-7912, ^email: fforptm@ku.ac.th. \\ ${ }^{2}$ World Wildlife Fund Thailand. Bangkok 10400, Thailand \\ ${ }^{3}$ Department of Civil Engineering, Faculty of Engineering, Kasetsart University. Bangkok 10900, Thailand
}

Manuscript received: 17 March 2020. Revision accepted: 6 May 2020.

\begin{abstract}
Rinnamang S, Sirirueang K, Supavetch S, Meunpong P. 2020. Estimation of aboveground biomass using aerial photogrammetry from unmanned aerial vehicles in teak (Tectona grandis) plantation in Thailand. Biodiversitas 21: $2369-2376$. Thailand is one of the best teak planting locations in the world. Teak (Tectona grandis Linn.f.) is one of the most species planting and a significant source of high-value timber in Thailand. For plantation management, biomass is one of the important factors while determining the production of a plantation and also for sustainable forest management. Unmanned Aerial Vehicles (UAV) have the ability to produce 3D RGB digital images which can be used to study the plantation characteristics. This study aimed to use aerial images and photogrammetry techniques derived from unmanned aerial vehicles (UAV) to estimate teak biomass in Thong Pha Phum plantation, Kanchanaburi Province, Thailand. We conducted our study on 15-and 36-year-old teak stands, and compared the tree dimension between data obtained from field measurement and that from aerial images and photogrammetry techniques. In the 15-yearold stand, the average tree height estimated from the UAV and ground-truthing were 12.34 and $13.06 \mathrm{~m}$, respectively. In the 36-year-old stand, the average tree height from the UAV and ground-truthing were 28.87 and $29.39 \mathrm{~m}$, respectively. We found that in both stands, the difference between data generated from the UAV and ground-truthing data was not significant $(\mathrm{p}$-value $=0.07$ and 0.306 , respectively). There was also a strong correspondence between tree height estimated from the UAV and that measured on the ground which is indicated by the high $\mathrm{R}^{2}$ (i.e. 0.70 and 0.64 for the 15 -and 36 -year-old stands, respectively). Using UAV generated data, the total biomass of 15-and 36-year-old stands was estimated to be around $42.07 \mathrm{t} \mathrm{ha}^{-1}$ and $67.13 \mathrm{t} \mathrm{ha}^{-1}$, respectively. The overall results suggest that UAV can be used as an effective tool to survey and monitor stand's productivity in teak plantation.
\end{abstract}

Keywords: Aerial photogrammetry, biomass, teak plantation, unmanned aerial vehicle, UAV

\section{INTRODUCTION}

Forest inventory is an important process to collect information that can be used in planning and management operations for sustainable utilization of forest resources (Otero et al. 2018). Above-ground biomass is one of the most common parameters used to measure forest production and through which, the volume and carbon stock of the stand can be estimated (Somogyi et al. 2006). Forest stand biomass can be calculated by using allometric equations and dimensions of trees, such as the diameter and total height (Edson and Wing 2011, Durkaya et al. 2013). However, manual measurement of the tree dimensions can be arduous and time-consuming, with some areas being difficult to access (Navarro et al. 2019). Therefore, remote sensing (RS) techniques such as satellite imagery, LiDAR, or aerial photogrammetry have been developed to estimate the forest biomass (Jayathunga et al. 2018).

Recently, Unmanned Aerial Vehicle (UAV) technology has been widely used for studying the forest structure (Aicardi et al. 2017, Adão et al. 2017, Shahbazi et al. 2014). UAV photogrammetry can provide high-resolution digital images at local scales. The advantages of UAV are low-cost, surveying large areas while saving time, and ability to access areas that may be hard to survey (Tang and Shao 2015, Webster et al. 2018). Digital photogrammetry generated from UAV imagery can provide 3D data, which can be used to measure tree height data. This data can be used in the estimation of forest production parameters, such as volume, biomass, and carbon stocks (Lim et al. 2015, Lisein et al. 2013, Zarco-Tejada et al. 2014). Using UAV imagery, tree height estimates can be derived from a canopy height model (CHM) by subtracting a digital terrain model (DTM) from a digital surface model (DSM) (Panagiotidis et al. 2017).

Teak (Tectona grandis Linn.f.) is a light-demanding species with a rounded crown, large leaf, and long clear bole, and it is able to resist fire (Koonkhunthod et al. 2007, Meunpong 2012). It is an important commercial tree with highly valued timber (Warner et al. 2017). Teak has various types of utilization depending on log size and tree age. The rotation length of teak plantation in Thailand is 30 years with $183.75 \mathrm{~m}^{3} \mathrm{ha}^{-1}$ timber volume (Royal Forest Department 2010).

In Thailand, teak has been planted extensively in the Northern and Western regions of the country. The Forest Industry Organization (FIO) is a government state enterprise belonging to the Thai Ministry of Natural 
Resources and Environment (MNRE). Throughout Thailand, FIO has 245 plantations (184,000 ha) dominated by teak (80,000 ha) and fast-growing exotic species such as Eucalyptus spp. One of the aims of FIO is to issue standard certification for sustainable forest management practices (Forest Industry Organization 2016). In 2018, teak harvesting area of FIO was 4,924 ha and gained US\$16.72 million from $67,495 \mathrm{~m}^{3}$ timber production (Forest Industry Organization 2018a). FIO's tree census was done every year in 0.15 ha ( 3 plots of 0.05 ha circular plot) per age class. Therefore, data acquired from small areas of census plots were converted to inaccurate total timber production. Furthermore, many errors of data will occur with unskilled staff. Moreover, the forest inventory of FIO proceeded by local officers take a lot of time and spend a lot of budgets. The objective of this study was to quantify teak biomass using UAV imagery and photogrammetry processes.

\section{MATERIALS AND METHODS}

\section{Study area}

The study area is located in the Thong Pha Phum plantation in Kanchanaburi Province, Thailand (Figure 1). The plantation belongs to the FIO, which has been planting trees to be used in timber production since 1978. This extensively managed plantation is one of the largest plantations in the Western region, and was, therefore, a suitable area for such a study. The plantation area is dominated by teak stands, covering an area of 2,372 ha or $71 \%$ of the total area. The elevation of the plantation is around $400 \mathrm{~m}$ asl (above sea level) with the annual rainfall ranges between 1,600 and $2,000 \mathrm{~mm} \mathrm{year}^{-1}$. This area originally was a mixed deciduous forest, and thus bamboo is also found in the plantation (Forest Industry Organization 2018b).

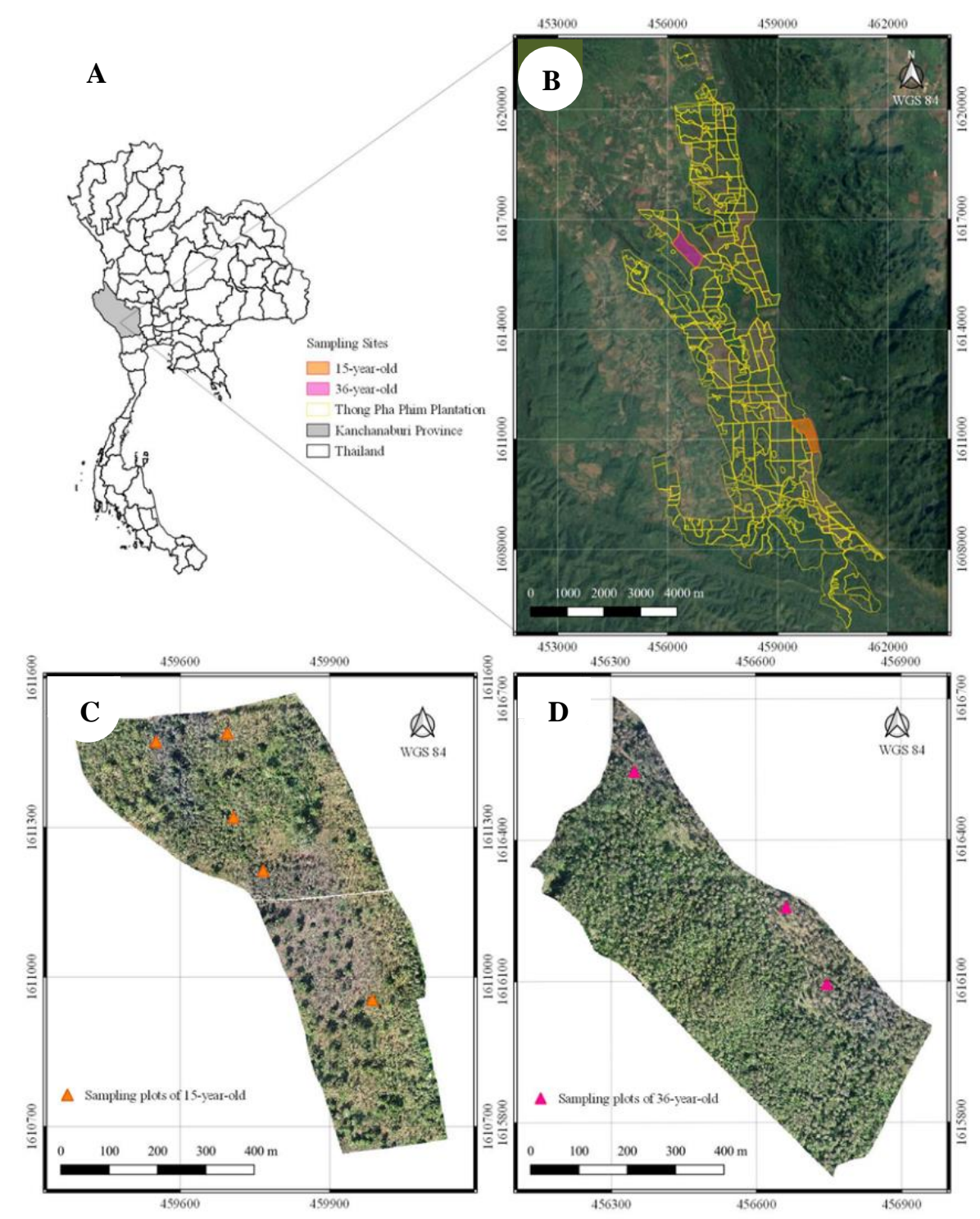

Figure 1. Map of study area in the Thong Pha Phum plantation in Kanchanaburi Province, Thailand. A. Kanchanaburi Province, Thailand; B. Production area in the Thong Pha Phum plantation; C. Ortho-image of a 15-year-old teak stand; D. Ortho-image of a 36year-old teak stand. 


\section{Data acquisition}

We selected 2 stands of different ages: i.e. 15-year-old stand (148 ha in total) with the thinning cut for timber production, and 36-year-old stand (90 ha in total) for the final harvest. All the trees were planted at a spacing of $4 \mathrm{~m}$ $\times 4 \mathrm{~m}$ for profitability and efficiency of the management of the teak plantation at sites of medium and poorer quality (Noda and Himmapan 2014). In Thailand, very few studies on forest inventory and timber production by using UAV. Therefore, this present study tries to develop the guidelines for estimating teak yields by using data acquired from UAV. The results can be used for plantation management of FIO at acceptable cost. The number of sample plots was determined as 0.5 percent of total production area in each stand, and the plots were randomly located (Viriyabuncha et al. 2001). Each plot had a size of $40 \mathrm{~m} \times 40 \mathrm{~m}$, it resulted in 5 and 3 of sample plots at the 15-and 36-year-old stand, respectively. The coordinates of these plots were recorded at each corner of each plot by using a Garmin ETREX Vista Cx handheld GPS. All the trees in sample plots were measured for their diameter at breast height (DBH) using a diameter tape (Lufkin Executive Thin line), total height using a digital altimeter (Haglof Vertex Laser Geo), and the coordinates of each tree using a handheld GPS. Aerial images were taken by using a DJI Phantom 4 Pro multirotor UAV with a $20 \mathrm{M}$ pixel CMOS sensor and RGB camera. The altitude of each flight was set between 100 and $170 \mathrm{~m}$, depending on the height of the trees. The front overlap was set to be $80 \%$ of an image and $70 \%$ of side overlap using Pix4D Capture software (Thomkrajang 2017).

\section{Data processing}

Aerial images were processed by using the Pix4D software to create a DSM, DTM, and an Ortho-image for quantifying the tree height (Lim et al. 2015; Zainuddin et al. 2016). Thereafter, an Ortho-image was used to position the center of the crown by using photogrammetry processes in Python language. In the Ortho-images, the natural-color imagery was blurred for smoothing the edge of each pixel and reducing some noise or reducing the effect of oddly colored dots in the images caused by small branches and their shadows within the crown (Pitkänen et al. 2004). After that, the colored images were converted into grayscale images by subtracting the green and red bands from the RGB image. Threshold values were determined for changing the gray image into a binary image where white represented the tree crown and black pixels represented the ground. We used watershed-segmentation algorithm to delineate a tree crown boundary in the binary image for separating individual tree crowns (Kaartinen et al. 2012). After the tree crown boundaries were constructed, the contour lines were established through the image moment algorithm to calculate the center and radius of each tree canopy. Thereafter, the individual radius of a given canopy was represented as the number of pixels. Crown cover of each tree was calculated by multiplying the number of pixels with the Ground Sampling Distance (GSD). Tree height was derived from the CHM. CHM was calculated by subtracting the DSM from the DTM by using Quantum
GIS (Khosravipour et al. 2015; Mohan et al. 2017). Tree heights were calculated from the raster layer which used the highest pixel values within a polygonal vector layer of the crown by Zonal Statistics plugin in QGIS (Panagiotidis et al. 2017).

Ground truthing of $\mathrm{DBH}$, total height, DBH-height frequencies, tree density (tree ha $\left.{ }^{-1}\right)$, and stem basal area $\left(\mathrm{m}^{2}\right.$ $\mathrm{ha}^{-1}$ ) was calculated by using the inventory data from sampling plots. Linear regression analysis was used to determine the relationship between tree height obtained from ground truth and photogrammetry. Tree height was then used as a prediction variable to calculate the $\mathrm{DBH}$ of each tree detected in Ortho-image by using a non-linear regression model to determine the relationship between total height and DBH from ground-truthing data. Finally, the individual total height and $\mathrm{DBH}$ derived from the regression model were used to calculate the Above Ground Biomass (AGB), which was estimated based on the allometric equations reported by Diloksumpun et al. (2011), who studied the same plantation area (Table 1). The various steps and processes undertaken in the estimation are shown in Figure 2.

\section{RESULTS AND DISCUSSION}

Stand characteristics of the 15-and 36-year-old teak stands

The 36-year-old teak stand had a larger variation in the DBH and height compared to the 15-year-old stand (Figure 3) due to differences in growth rate of individual trees remaining in the mature stand. In addition, this plantation used a selective thinning by removing all small trees which resulted in uncertain tree growth pattern of remaining stand (Pe'rez and Kanninen 2005). Moreover, the variations in diameter and height of teak depend on-site quality (Koonkhunthod et al. 2007). Our results showed that that the 15-year-old teak stand had a higher density of trees when compared to the 36-year-stand. However, the basal area of the older stand was larger than the younger stand (Table 2). Difference in tree density was found when compared to Diloksumpun et al. (2011) who studied in a similar area (Table 2) using difference plot size $(60 \mathrm{~m} \times 60$ m). A similar result was reported by Thongfak (2012), who also studied such stands in Thong Pha Phum plantation and found that when teak stand became mature, the stand density was decreased and the tree became larger relative to the younger stands.

Table 1. Allometric equations for the estimation of teak biomass in Thong Pha Phum plantation, Kanchanaburi Province $(n=21)$ (Diloksumpun et al. 2011).

\begin{tabular}{lll}
\hline Tree part & Equation & $\mathbf{R}^{2}$ \\
\hline Stem & $0.0201\left(\mathrm{DBH}^{2} \mathrm{Ht}^{0.9781}\right.$ & 0.9946 \\
Leave & $0.004\left(\mathrm{DBH}^{2} \mathrm{Ht}\right)^{0.8916}$ & 0.8271 \\
Branch & $0.0047\left(\mathrm{DBH}^{2} \mathrm{Ht}\right)^{0.8876}$ & 0.6911 \\
Total & $0.0251\left(\mathrm{DBH}^{2} \mathrm{Ht}\right)^{0.9801}$ & 0.9937 \\
\hline
\end{tabular}

Note: $\mathrm{DBH}=$ Diameter at breast height $(\mathrm{cm}), \mathrm{Ht}=$ Total height of tree $(\mathrm{m})$ 


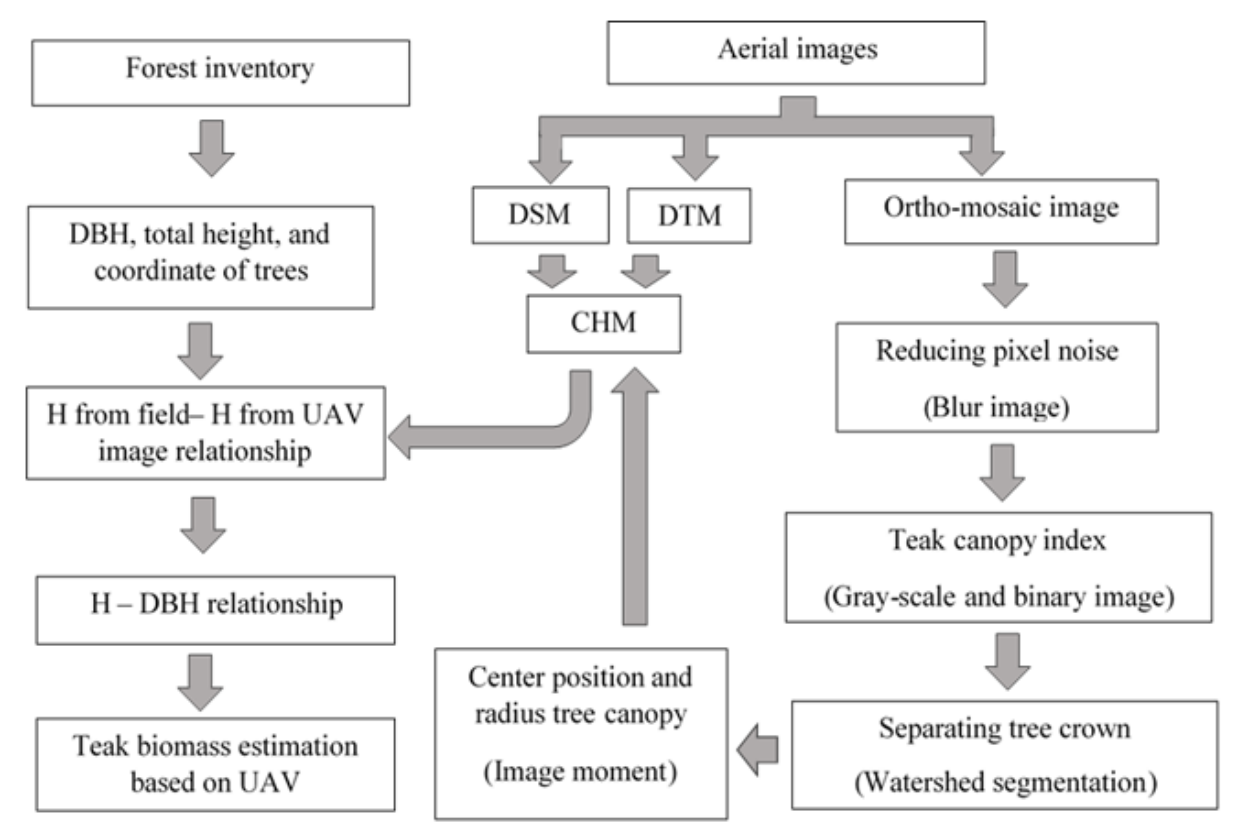

Figure 2. Workflow implemented in this study representing the analysis and output

\section{Ortho-images and tree height of 15-and 36-year-old teak plantation}

We acquired 370 images at the 15-year-old stand with a $2 \mathrm{~cm}$ GSD and 741 images at the 36-year-old stand with a 5 $\mathrm{cm}$ GSD. For each stand, an RGB ortho-image was generated by using the Pix4D software to identify individual trees in each sampling plot and in the whole area. The Ortho-image was then converted into blur-gray image, binary image, and a segmentation process, respectively, to separate each tree crown (Figure 4). The accuracy of successfully identifying trees using photogrammetry processes of Ortho-image was $92 \%$ and $83 \%$ for the 15-and 36-year-old stands, respectively. The stand with homogeneous trees and sparsely distributed trees provided a higher level of tree detection. Grznárová et al. (2019) found a detection rate of $95 \%$ in coniferous trees and $71 \%$ in deciduous trees using Watershed Segmentation method. For our results, trees with double main canopies, small replanted trees, and trees that occurred in the shadow of canopy of adjacent taller trees could not be detected.

The total tree height was compared between the ground-truthing and photogrammetry data. For this study, we considered only those trees which occurred both in UAV images and trees found in the study plots. In the 15year-old stand, the average total height from groundtruthing was $13.06 \mathrm{~m}(7.57-17.70 \mathrm{~m})$ compared to $12.34 \mathrm{~m}$ $(8.34-16.71 \mathrm{~m})$ from the photogrammetry techniques. However, there was no significant difference $(\mathrm{p}$-value $=$ 0.07 ) between both data sets. In the 36-year-old stand, the average tree height was $29.39 \mathrm{~m}(25.47-32.70 \mathrm{~m})$ and 28.87 $\mathrm{m}$ (24.01-32.08 m) as obtained from the ground-truthing and photogrammetry, respectively. There was a nonsignificant difference ( $\mathrm{p}$-value $=0.31$ ) between these data sets. However, the total height from ground-truthing seemed to be higher than the data derived from the UAV images (Figure 5) because of the uncertainty in DTM due to highly dense crown and bamboo clumps. The dense canopy has limitations to identify the ground points for adequate quality DTM creating in the forest stands (Grznárová et al. 2019, Zarco-Tejada et al. 2014). Other studies by Otero et al. (2018) in mangrove forest found a significant difference of $1.3 \mathrm{~m}$ when comparing the height between the ground-truthing and the CHM data when considered only the trees from the upper canopy in the productive zone of the mangrove forest. The tree height estimate tends to overestimation due to the inconsistency and inaccuracy of using the instrument when measuring the tree height (i.e. Haga Altimeter), and because of the creation of CHM that was the acceptable error of estimates from the UAV (Otero et al. 2018).

A linear regression model was constructed to determine the relationship between tree height derived from photogrammetry (h) and ground truth data (h') of the 15and 36-year-old stand. Figure 6 shows that a better correspondence was found between $h$ and $h$ ' in the 15-yearold stand compared to the older stand. Panagiotidis et al. (2017) found a strong relationship between the UAV estimated and the field measured tree heights with ranges of $\mathrm{R}^{2} \quad 0.72-0.75$ in a temperate forest in the Czech Republic. Anyway, mature trees had the ranges of variation between the estimated height from UAV and ground truth data wider than the younger trees.

\section{Teak biomass estimation}

The DBH and total height of trees estimated from ground-truthing were fitted using non-linear regression models and then were used to estimate the standing biomass. In the 15-year-old plot, a clear trend with a higher correlation coefficient $\left(\mathrm{R}^{2}=0.62\right)$ was obtained when compared to the older stand $\left(\mathrm{R}^{2}=0.52\right)$ (Figure 7$)$. All tree 
heights in each study area derived from UAV images were used for determining the diameter of each tree. After that, DBH and height were used as parameters in biomass equation (Diloksumpun et al. 2011). The total biomass of 15-and 36-year-old stand based on the UAV data was 42.07 and $67.13 \mathrm{t} \mathrm{ha}^{-1}$, respectively. On the other hand, derived from ground-truthing data, the total biomass of the 15-yearold was $41.50 \mathrm{t} \mathrm{ha}^{-1}$ and $84.28 \mathrm{t} \mathrm{ha}^{-1}$ in the 36-year-old, respectively. The number of identified trees and tree heights through photogrammetry processes greatly affected the biomass estimation in both stands. Therefore, some other tree species were added to the results due to unclear objects and inaccurate species identification. In the 15year-old stand, the other species (e.g. bamboo) which higher of total height than teak were removed before teak biomass estimation.
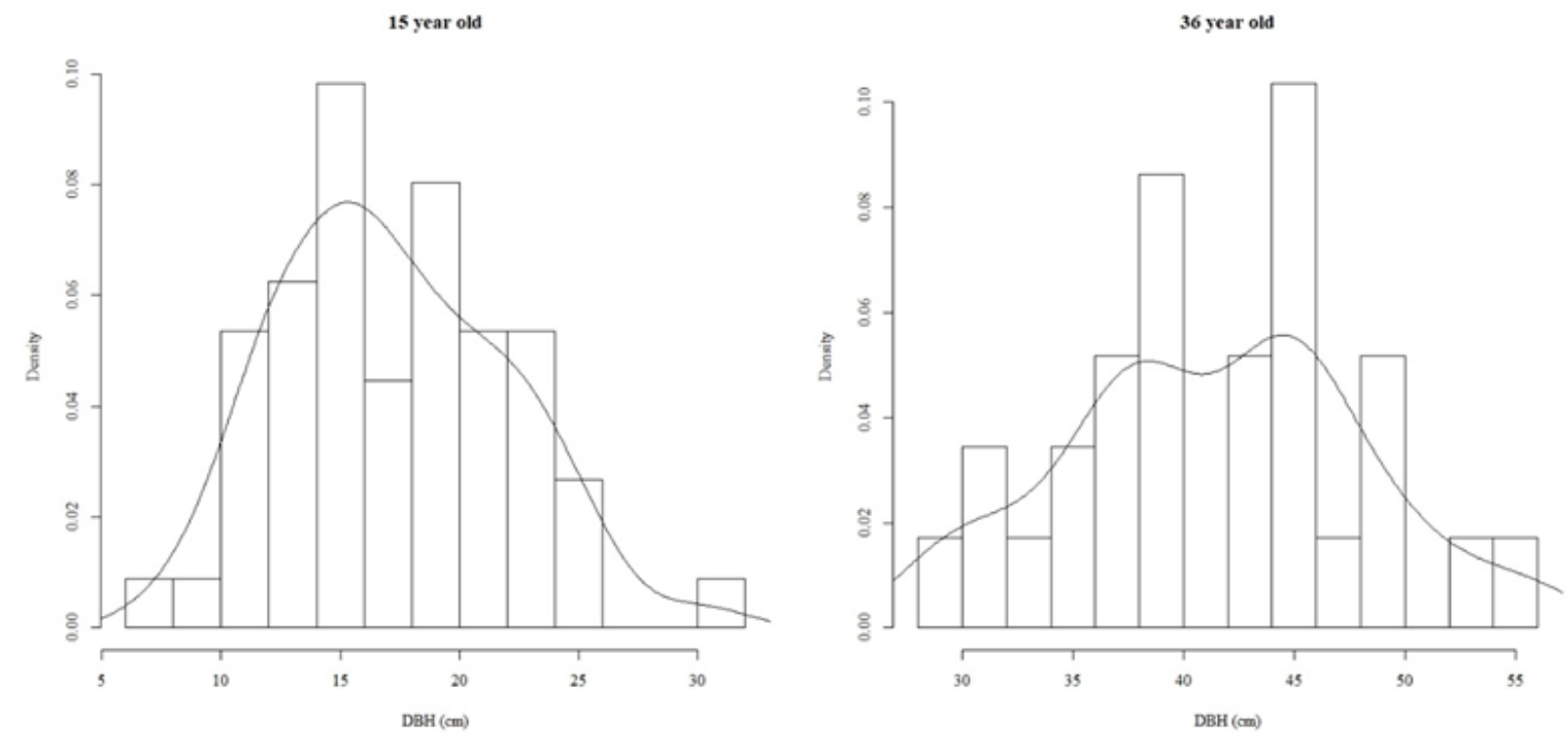

Figure 3. DBH frequency of the 15- (left) and 36-year-old (right) stands
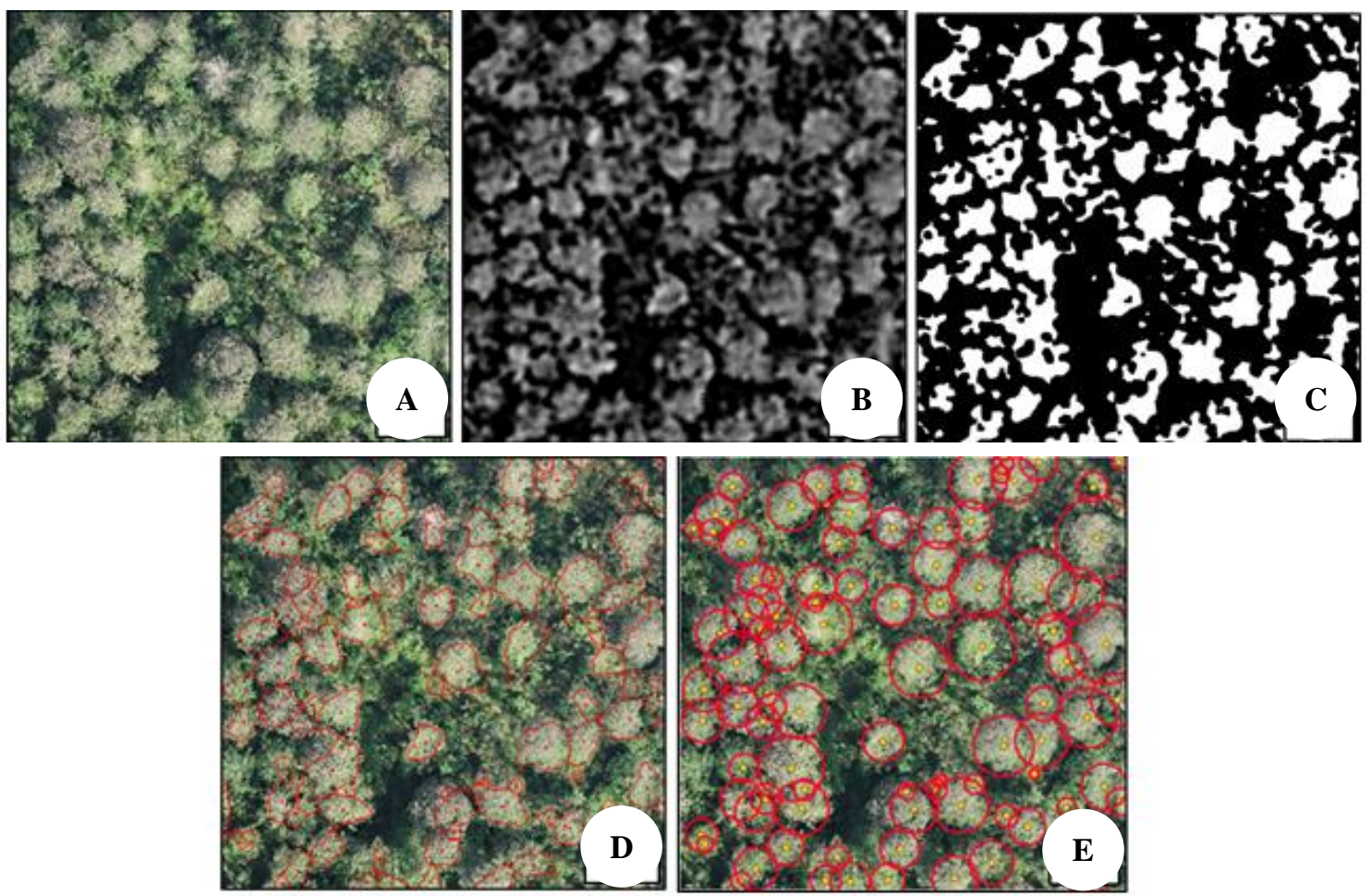

Figure 4. Photogrammetry processes: A. Ortho-image; B. Single band image; C. Binary image; D. Delineation crown of teak image; and E. Center position and canopy cover 

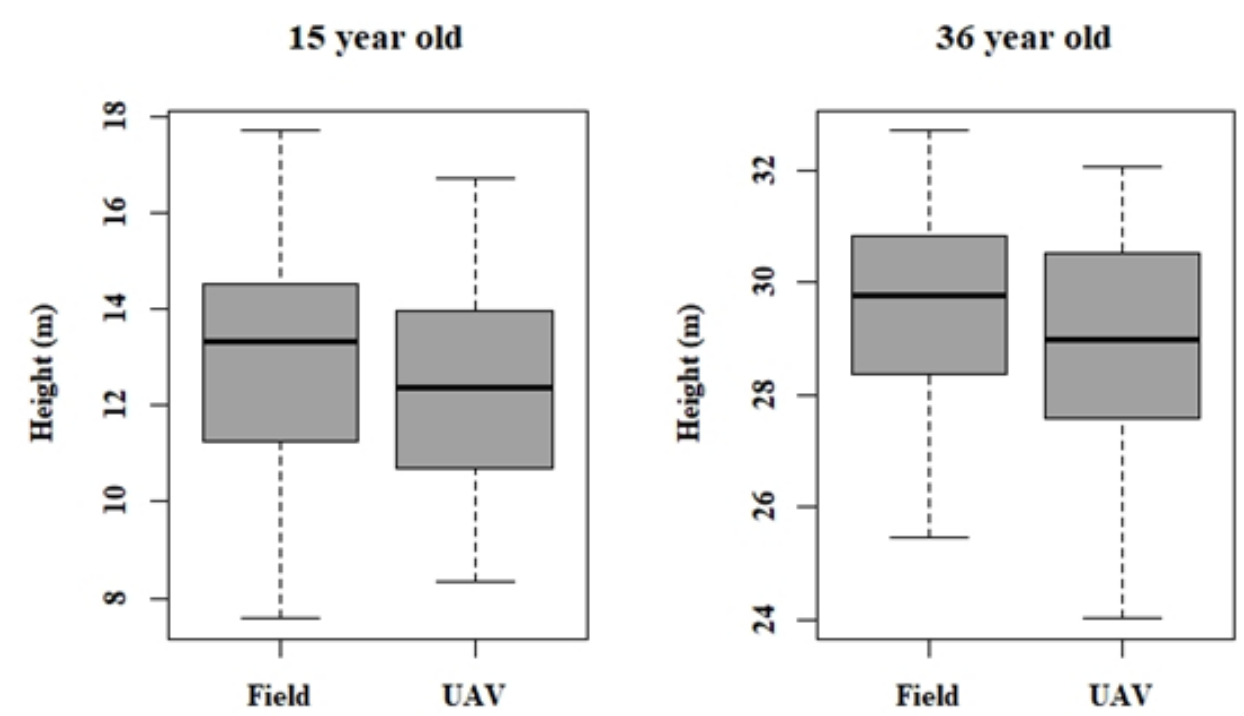

Figure 5. Comparison between tree height derived from ground truth and photogrammetry at the 15- (left) and 36-year-old (right) stands
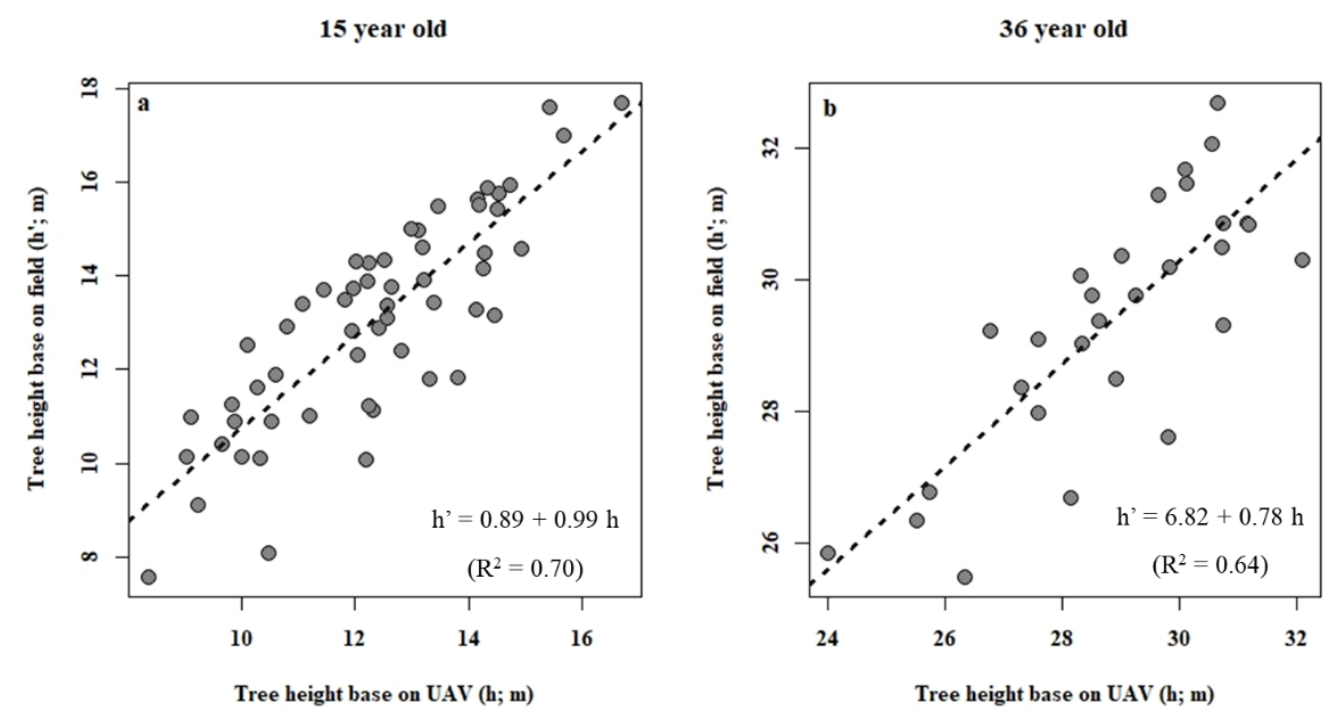

Figure 6. Linear regression models showing the relationship between tree height derived from ground truth and photogrammetry at the 15- (left) and 36-year-old (right) stands

Table 2. Tree density, tree height, DBH, basal area and teak biomass $\left(\mathrm{t} \mathrm{ha}^{-1}\right)$ of 15 and 36 years stand in this study and other studies

\begin{tabular}{|c|c|c|c|c|c|c|c|}
\hline \multirow{2}{*}{$\begin{array}{l}\text { Stand } \\
\text { age } \\
\text { (year) }\end{array}$} & \multirow[b]{2}{*}{$\begin{array}{l}\text { Tree density } \\
\left(\mathrm{t} \mathrm{ha}^{-1}\right)\end{array}$} & \multicolumn{4}{|c|}{ Ground truth data } & \multirow{2}{*}{$\begin{array}{c}\text { Total biomass } \\
\text { base on UAV data } \\
\left(t \text { ha }^{-1}\right)\end{array}$} & \multirow[b]{2}{*}{ References } \\
\hline & & $\begin{array}{l}\text { Tree height } \\
\text { (m) }\end{array}$ & DBH (cm) & $\begin{array}{c}\text { Basal area } \\
\left(\mathbf{m}^{2} \mathbf{h a}^{-1}\right)\end{array}$ & $\begin{array}{c}\text { Total biomass } \\
\quad\left(\mathrm{t} \mathrm{ha}^{-1}\right)\end{array}$ & & \\
\hline \multirow[b]{2}{*}{15} & 455 & $13.1 \pm 0.3$ & $17.2 \pm 0.6$ & 10.5 & 41.50 & 42.07 & \multirow{2}{*}{$\begin{array}{l}\text { This study } \\
\text { (Diloksumpun et al. 2011) }\end{array}$} \\
\hline & 614 & 17.9 & 17.27 & - & 81.32 & - & \\
\hline & 120 & $29.4 \pm 0.4$ & $41.4 \pm 1.3$ & 16.3 & 84.28 & 67.13 & This study \\
\hline 36 & 252 & $14.14 \pm 1.68$ & $28.42 \pm 2.56$ & - & 73.57 & - & $\begin{array}{l}\text { (Kongmeesup and } \\
\text { Boonyanuphap 2019) }\end{array}$ \\
\hline
\end{tabular}


15 year old

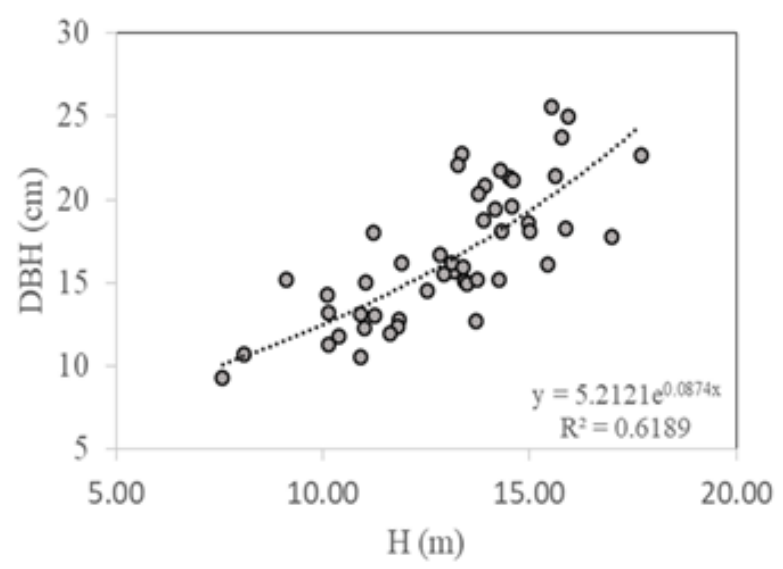

36 year old

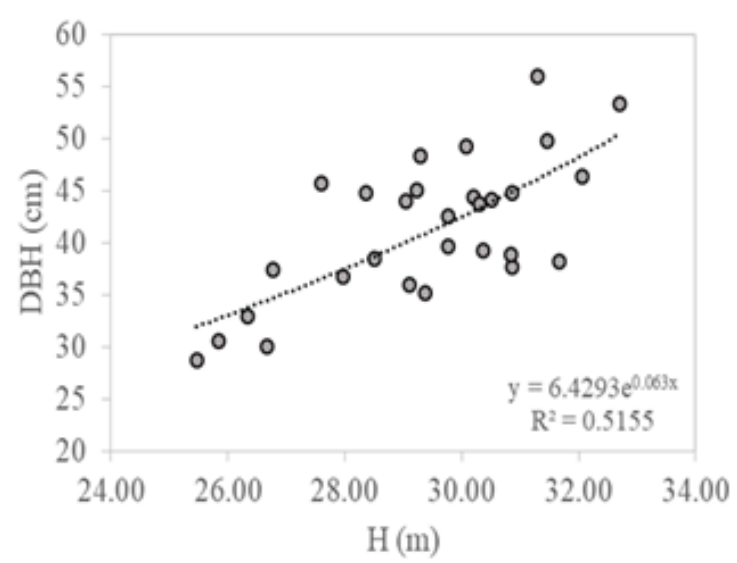

Figure 7. A non-linear regression model between DBH $(\mathrm{cm})$ and total height $(\mathrm{m})$ based on ground-truthing at the 15- $($ left $)$ and 36-yearold (right) stands

However, the teak biomass in the 15-year-old stand was lower than that reported by Diloksumpun et al. (2011) who also studied the 15-year-old stand in the same study site. Kongmeesup and Boonyanuphap (2019) reported the comparable results of total biomass from a 36-year-old stand in the lower northern part of Thailand (Table 2). Although, the size of tree of that report was slightly different from our study, the tree density was significantly different. Therefore, the total biomass of both sites was comparable. The difference in tree size could be due to difference in site quality in each stand. The area of our study had higher annual rainfall than the lower northern part of Thailand $\left(1748.8 \mathrm{~mm}_{\text {year }}{ }^{-1}\right)$, which would affect the growth rate of teak. However, in general, an increasing trend of biomass with age, tree density, site quality, and also tree size has been reported (Chaturvedi and Raghubanshi 2015, Pe'rez and Kanninen 2003). Uncertainty in data collection also resulted in a higher error of biomass, for example, manual Haga altimeter is likely to produce higher error than digital altimeter (Otero et al. 2018).

From our point of view, UAV was able to obtain rapidly and accurately the vegetation structure data and explore the whole area of the production area in the plantation. The rotary-wing UAV had the ability for takeoff and landing vertically, so the user can operate within a smaller vicinity. The photogrammetry process can be used to estimate the biomass of teak automatically which can save time and cost also, facilitating more frequent monitoring at each age stand. On the other hand, UAV imagery did not include ground control point (GCP) data, which is used to correct the errors related to coordinate location of each tree. The tree location acquired from handheld GPS was difficult to match with the location of the same tree derived from UAV images. This issue can be solved by using GPS receiver running in RTK (real-time kinematic) mode or the azimuth-distance from the reference point to specify tree location (Zarco-Tejada et al. 2014, Grznárová et al. 2019). Lastly, for better results, aerial photography should be done in different seasons, for e.g. during dry season, to detect terrain and in rainy season, to detect the full leaf canopy. Furthermore, flight plans should have the GCP to increase the global accuracy of drone maps.

In conclusion, this study attempted to estimate the teak biomass using high-resolution imagery from UAV with photogrammetry processes. The RGB imageries derived from UAV with flight altitude of $100 \mathrm{~m}$ for the 15 -year-old stand and $170 \mathrm{~m}$ for the 36-year-old stand resulted in sufficiently high-resolution images (GSD 2 and $3 \mathrm{~cm}$, respectively) and could be used to generate a digital surface model (DSM) and digital terrain model (DTM) to construct the canopy height model (CHM). Tree height estimation from CHM was a close correspondence with ground truth data. The Ortho-images were used to detect all trees coordinates. Such photogrammetry techniques had more accuracy in identifying trees in younger stand $(92 \%)$ compared to the mature stand $(83 \%)$. The tree height and biomass estimated from the UAV data showed more accurate results when compared to the results from field data. Furthermore, the use of rotary-wing UAV with photogrammetry processing is continuously increasing and developing. This technique can be flexible, low cost, and acquire acceptable error data. Therefore, UAV has the potential to acquire data that can be used for assessing forest production instead of traditional ground surveying.

\section{ACKNOWLEDGEMENTS}

This research was supported in part by the Graduate Program Scholarship from The Graduate School, Kasetsart University, Bangkok, Thailand. We would like to thank the 
local staff of FIO at the Thong Pha Phum Plantation for their assistance during the forest inventory.

\section{REFERENCES}

Adão T, Hruška J, Pádua L, Bessa J, Peres E, Morais R, Sousa J. 2017 Hyperspectral imaging: a review on UAV-based sensors, data processing and applications for agriculture and forestry. Remote Sens 9 (11): 1110-1140.

Aicardi I, Dabove P, Lingua AM, Piras M. 2017. Integration between TLS and UAV photogrammetry techniques for forestry applications. iForest-Biogeosci For 10 (1): 41-47.

Chaturvedi RK, Raghubanshi AS. 2015. Allometric Models for accurate estimation of aboveground biomass of teak in tropical dry forests of India. For Sci 61 (5): 938-949.

Diloksumpun S, Wachrinrat C, Chumsangsri T. 2011. An assessment of carbon storage in biomass of teak (Tectona grandis Linn.f) at Thong Phaphum Plantation. Proceeding of Research Exhibition on the Research Path Kasetsart University 2011. Kasetsart University, Bangkok, 28 January-5 February 2011. [Thailand]

Durkaya B, Durkaya A, Makineci E, Karaburk T. 2013. Estimating aboveground biomass and carbon stock of individual trees in uneven-aged Uludag Fir stands. Fresenius Environ Bull 22 (2): 428-434.

Edson C, Wing MG. 2011. Airborne Light Detection and Ranging (LiDAR) for individual tree stem location, height, and biomass measurements. Remote Sens 3 (11): 2494-2528.

Forest Industry Organization. 2016. Sustainable forest Management of Forest Industry Organization Policy. Forest Industry Organization, Bangkok, Thailand.

Forest Industry Organization. 2018a. Forest Industry Organization Action Plan 2018. Forest Industry Organization, Bangkok, Thailand.

Forest Industry Organization. 2018b. Thong Pha Phum Forest Plantation Management Summary. Forest Industry Organization, Bangkok, Thailand.

Grznárová A, Mokroš M, Surový P, Slavík M, Pondelík M, Merganič J. 2019. The crown diameter estimation from fixed wing type of UAV imagery. ISPRS-Int Arch Photogrammetry Remote Sens Spat Inf Sci XLII-2/W13: 337-341.

Jayathunga S, Owari T, Tsuyuki S. 2018. The use of fixed-wing UAV photogrammetry with LiDAR DTM to estimate merchantable volume and carbon stock in living biomass over a mixed conifer-broadleaf forest. Intl J Appl Earth Observation Geoinf 73: 767-777.

Kaartinen H, Hyyppä J, Yu X, Vastaranta M, Hyyppä H, Kukko A, Holopainen M, Heipke C, Hirschmugl M, Morsdorf F, Naessert E, Pitkanen J, Popescu S, Soberg S, Wolf BM, Wu J-C. 2012. An international comparison of individual tree detection and extraction using airborne laser scanning. Remote Sens 4 (4): 950-974.

Khosravipour A, Skidmore AK, Wang T, Isenburg M, Khoshelham K. 2015. Effect of slope on treetop detection using a LiDAR Canopy Height Model. ISPRS J Photogrammetry Remote Sens 104: 44-52.

Kongmeesup I, Boonyanuphap J. 2019. Estimation of carbon offset for teak plantation in lower northern Thailand. Songklanakarin J Sci Technol 41 (3): 580-586.

Koonkhunthod N, Sakurai K, Tanaka S. 2007. Composition and diversity of woody regeneration in a 37 -year-old teak (Tectona grandis L.) plantation in Northern Thailand. For Ecol Manag 247 (1-3): 246-254.

Lim YS, La PH, Park JS, Lee MH, Pyeon MW, Kim JI. 2015. Calculation of tree height and canopy crown from drone images using segmentation. J Korean Soc Surveying Geodesy Photogrammetry Cartography 33 (6): 605-613.

Lisein J, Pierrot-Deseilligny M, Bonnet S, Lejeune P. 2013. A photogrammetric workflow for the creation of a forest canopy height model from small unmanned aerial system imagery. Forests 4 (4): 922-944.

Meunpong P. 2012. Nutrient and Carbon Storage in Forest Plantation, Prachuap Khiri Khan province, Thailand. [Dissertation]. Kasetsart University, Bangkok. [Thailand]
Mohan M, Silva CA, Klauberg C, Jat P, Catts G, Cardil A, Hudak AT, Dia M. 2017. Individual tree detection from unmanned aerial vehicle (UAV) derived canopy height model in an open canopy mixed conifer forest. Forests 8 (9): 340-357.

Navarro JA, Alfredo N, Fernández-Landa A, Esteban J, RodríguezNoriega P, Guillén-Climent ML. 2019. Integration of UAV, Sentinel1 , and Sentinel-2 data for mangrove plantation aboveground biomass monitoring in Senegal. Remote Sens 11 (1): 77-100.

Noda I, Himmapan W. 2014. Effects of silvicultural alternatives on model-based financial evaluation of teak (Tectona grandis L.) farm forestry management for small-scale farmers in Northeast Thailand. Open J For 4 (5): 558-569.

Otero V, Kerchove RVD, Satyanarayana B, Martínez-Espinosa C, Fisol MAB, Ibrahim MRB, Sulong I, Mohd-Lokman H, Lucas R, Dahdouh-Guebas F. 2018. Managing mangrove forests from the sky: forest inventory using field data and unmanned aerial vehicle (UAV) imagery in the Matang Mangrove Forest Reserve, Peninsular Malaysia. For Ecol Manag 411: 35-45.

Panagiotidis D, Abdollahnejad A, Surový P, Chiteculo V. 2017. Determining tree height and crown diameter from high-resolution UAV imagery. Intl J Remote Sens 38 (8-10): 2392-2410.

Pe'rez D, Kanninen M. 2003. Aboveground biomass of Tectona grandis plantations in Costa Rica. Trop For Sci 15 (1): 199-213.

Pe'rez D, Kanninen M. 2005. Stand growth scenarios for Tectona grandis plantations in Costa Rica. For Ecol Manag 210: 425-441.

Pitkänen J, Maltamo M, Hyyppä J, Yu X. 2004. Adaptive methods for individual tree detection on airborne laser-based canopy height model. Proceedings of ISPRS Workshop Laser-Scanners for Forest and Landscape Assessment. In International Archives of Photogrammetry, Remote Sensing and Spatial Information Sciences; ISPRS. Vienna, Austria 36 (8/W2): 187-191. Freiburg, 3-6 October 2004. [Germany]

Royal Forest Department. 2010. Teak. Royal Forest Department, Bangkok, Thailand.

Shahbazi M, Théau J, Ménard P. 2014. Recent applications of unmanned aerial imagery in natural resource management. GISci Remote Sens 51 (4): 339-365.

Somogyi Z, Cienciala E, Mäkipää R, Muukkonen P, Lehtonen A, Weiss P. 2006. Indirect methods of large-scale forest biomass estimation. Eur J For Res 126 (2): 197-207.

Tang L, Shao G. 2015. Drone remote sensing for forestry research and practices. J For Res 26 (4): 791-797.

Thomkrajang T. 2017. Estimation of Carbon Sequestration in Community Forests using UAV Technique: A Case Study of Ban Bu Ta Tong Community Forests, Tambon Naklang, Sungnoen Districts, Nakhonratchasima Province. [Dissertation]. Chulalongkorn University, Bangkok. [Thailand]

Thongfak C. 2012. Biomass and Carbon Storage of Teak (Tectona grandis Linn.f) at Thongphaphum Plantation, Kanchanaburi Province. [Dissertation]. Kasetsart University, Bangkok. [Thailand]

Viriyabuncha C, Chittachumnonk P, Suthisrisinn C, Samran S, Peawsa-ad K. 2001. Adjusting equation to estimate the above-ground biomass of teak plantation in Thailand. Proceedings of the 7 th Silvicultural Seminar. Kasetsart University, Bangkok, 12-14 December 2001. [Thailand]

Warner AJ, Jamroenprucksa M, Puangchit L. 2017. Buttressing impact on diameter estimation in plantation teak ( Tectona grandis L.f.) sample trees in northern Thailand. Agric Nat Resour 51 (6): 520-525.

Webster C, Westoby M, Rutter N, Jonas T. 2018. Three-dimensional thermal characterization of forest canopies using UAV photogrammetry. Remote Sens Environ 209: 835-847.

Zainuddin K, Jaffri MH, Zainal MZ, Ghazali N, Samad AM. 2016. Verification test on ability to use low-cost UAV for quantifying tree height. Proceedings of the 2016 IEEE 12th International Colloquium on Signal Processing \& Its Applications (CSPA). Melaka, 4-6 March 2016. [Malaysia]

Zarco-Tejada PJ, Diaz-Varela R, Angileri V, Loudjani P. 2014. Tree height quantification using very high-resolution imagery acquired from an unmanned aerial vehicle (UAV) and automatic 3D photoreconstruction methods. Eur J Agron 55: 89-99. 